\title{
Ameloblastik Fibrosarkom: Nadir Bir Olgu Sunumu
}

\author{
Ameloblastic fibrosarcoma: A Rare Case Report
}

İrfan KARA ${ }^{1}$, Sedat ÇAĞLI' ${ }^{2}$,Serap DOĞAN ${ }^{3}$, Kemal DENIZ ${ }^{4}$, Yusuf Nuri KABA ${ }^{5}$

\author{
${ }^{1}$ Sütçü İmam Üniversitesi Tıp Fakültesi KBB Ana Bilim Dalı, Kahramanmaraş,Türkiye \\ ${ }^{2}$ Erciyes Üniversitesi Tıp Fakültesi KBB Ana Bilim Dalı,Kayseri,Türkiye \\ ${ }^{3}$ Erciyes Üniversitesi Tıp Fakültesi Patoloji Ana Bilim Dalı, Kayseri,Türkiye \\ ${ }^{4}$ Erciyes Üniversitesi Diş Hekimliği Fakültesi, Ağız Yüz Çene Cerrahisi Ana Bilim Dalı, Kayseri,Türkiye \\ ${ }^{5}$ Erciyes Üniversitesi Diş Hekimliği Fakültesi, Ağız Yüz Çene Cerrahisi Ana Bilim Dalı, Kayseri,Türkiye
}

\section{Özet}

Ameloblastik fibrosarkom (AFS) benign odontojenik epitel ve malign mezenkimal stromal komponentlerden oluşan nadir bir tümördür. Hastalı̆ıın ortalama görülme yaş 27.3 ’tür. On yıllık sağkalım oranlarına bakıldığında \%21.8 ile 83 arasında değişebilmektedir. Klinik evre, histolojik grade ve lokal rekürrens en önemli prognostik faktörlerdir. Sunulan hastanın başvuru şikayetleri çenede giderek artan şişlik ve ağrı idi. Hastalığın optimal tedavisi geniş cerrahi sınırlarla eksizyon ve uzun süreli takiptir. Adjuvan tedaviler ve boyun diseksiyonu tartışmalıdır. Hastaya hemimandibulektomi yapılarak kitle geniş sınırlarla eksize edilip post-operatif dönemde KRT verilmiştir. Bu yazıda nadir bir tümör olan mandibula kaynaklı AFS olgusu literatür eşliğinde sunulmuştur.

Anahtar kelimeler: Ameloblastik fibrosarkom, Mandibula, Tedavi

\section{Abstract}

Ameloblastic fibrosarcoma (AFS) is a rare tumor of benign odontogenic epithelium and malignant mesenchymal stromal components. The mean age of the disease is 27.3 years. The 10-year survival rates can vary from $21.8-83 \%$. Clinical stage, histological grade and local recurrence are the most important prognostic factors. Optimal treatment of the disease is excision with wide surgical margins and long-term follow-up. Adjuvant therapies and neck dissection are controversial. The patient underwent hemimandibulectomy and the mass was excised with wide margins and CRT was given in the post-operative period. In this article, a case of mandibular AFS which is a rare tumor is presented in the light of the literature.

Keywords: Ameloblastic fibrosarcoma, Mandible, Treatment

Yazışma Adresi: İrfan KARA, Sütçü İmam Üniversitesi KBB Kliniği Onikişubat/Kahramanmaraş,Türkiye

Telefon: 0536260 0692, Mail: drirfankara@gmail.com

ORCID No(Sirasiyla): 0000-0003-3884-3014, 0000-0003-4913-8687, 0000-0001-6331-2245, 0000-0001-7749-2152, 0000-0001-9221-4599

Geliş Tarihi: 17.09 .2020

Kabul Tarihi: 04.12.2020

DOI: $10.17517 / \mathrm{ksutfd} .795775$ 


\section{GíRiș}

Fibrosarkom; intraosseöz tümörler içinde nadir bir grup olup sıklığı \%5’tir ve sıklıkla uzun kemiklerden köken almaktadır. Vakaların \%10'u baş boyun bölgesinde izlenmekte olup en sık etkilenen kemik mandibuladır (1). Ameloblastik fibrosarkom (AFS) nadir görülen bir tümör olup atipik sitoloji, azalmış epitelyal komponent ile beraber artmış selülarite ve agresif davranış ile karekterizedir (2). Hastaların başvuru şikayetleri oral kavitede ağrı, şişlik, bazen diş kaybı, uyuşukluk ve üzerindeki mukozada ülserasyondur (3). AFS low grade bir sarkom olup erkeklerde görülme sıklığı hafifçe yüksektir ve ortalama görülme yaşı 27.3’tür (4). Bu yazıda nadir bir tümör olan AFS nedeniyle opere edilen 29 yaş kadın hasta sunulmuştur.

\section{OLGU SUNUMU}

Bir yıldır sağ çenede ağrı ve giderek büyüyen kitle şikayeti ile başvuran 29 yaş kadın hastanın yapılan fizik muayenesinde sağ temporal bölgeden başlayıp mandibula angulusuna kadar uzanan sert, bastırmakla hafif ağrılı, ağız açıklığında kısıtlılığa neden olan kitle tespit edildi. Oral kavite muayenesinde etkilenen bölgeye komşu mukoza sağlıklı görünümdeydi fakat kitle bukkal mukozada itilmeye sebep olmuştu ve sert palpe edildi.

Hastanın özgeçmişinden 7 yıl önce dış merkez diş hekimliği kliniğinde gömülü 20 yaş dişi ile ilişkili lezyonundan eksizyonel biyopsi yapıldığ 1 ve patolojisinin ameloblastoma olarak raporlandığı öğrenildi. Hastanın yine aynı bölgesin- de şişliği olması üzerine tekrar başvurduğu diş hekimliği kliniğinde 'mandibula yerleşimli kitle' nedeniyle biyopsi yapılmıştır.Hastanın patoloji sonucunun'ameloblastik fibrom zemininde gelişmiş sarkamatöz değişiklik" şeklinde raporlanması üzerine hasta kliniğimize yönlendirilmiştir. Hastanın çekilen panoramik mandibula grafisinde sağ premolar dişler bölgesinden başlayıp kondil bölgesine kadar uzanan, düzensiz sınırlı, içerisinde sklerotik septaların izlendiği radyolüsent lezyon izlendi (Resim 1). Maksillofasyal MR'da sağ mandibula koronoid proçesten başlayıp ramus mandibulaya uzanan, kemiği belirgin ekspanse eden ve geniş alanda kortikal perforasyona neden olan $62 \times 43 \times 31 \mathrm{~mm}$ boyutlarında kitle lezyonu izlendi. Lezyon anteromedialde mastikatör boşluğu dordurmuş olup santral kesiminde septasyonlar mevcuttu. Kitle T2 kesitlerde kasa göre hiperintens, T1A'da kasa göre hipointens, intravenöz kontrast madde sonrası diffüz belirgin kontrastlanma gösteriyordu (Resim 2-3). Maksillofasyal BT'de aynı lokalizasyonda hiperdens kitle lezyonu izlendi (Resim 4). PET BT'de uzak metastaz saptanmadi. Hastaya sağ hemimandibulektomi ve sağ 2.bölge boyun diseksiyonu yapıldı (Resim 5). Aynı seansta plastik cerrahi ekibi tarafından da serbest fibula grefti ile mabdibula rekonstrüksiyonu yapıldı. Patoloji sonucu "ameloblastom zemininde gelişmiş fibrosarkom" şeklinde raporlandı (Resim 6). Boyun diseksiyonu materyalinde patolojik lenf nodu saptanmadi. Hastaya post-operatif kemoradyoterapi (KRT) uygulandı (RT 30 fraksiyon 60 Gy, KT 4 kür İfosfamid, Mesna ve Doksorubisin). Hasta post-operatif 32.ayda olup takiplerinde nüks ve uzak metastaz bulgusu yoktur. (Hastadan yazılı

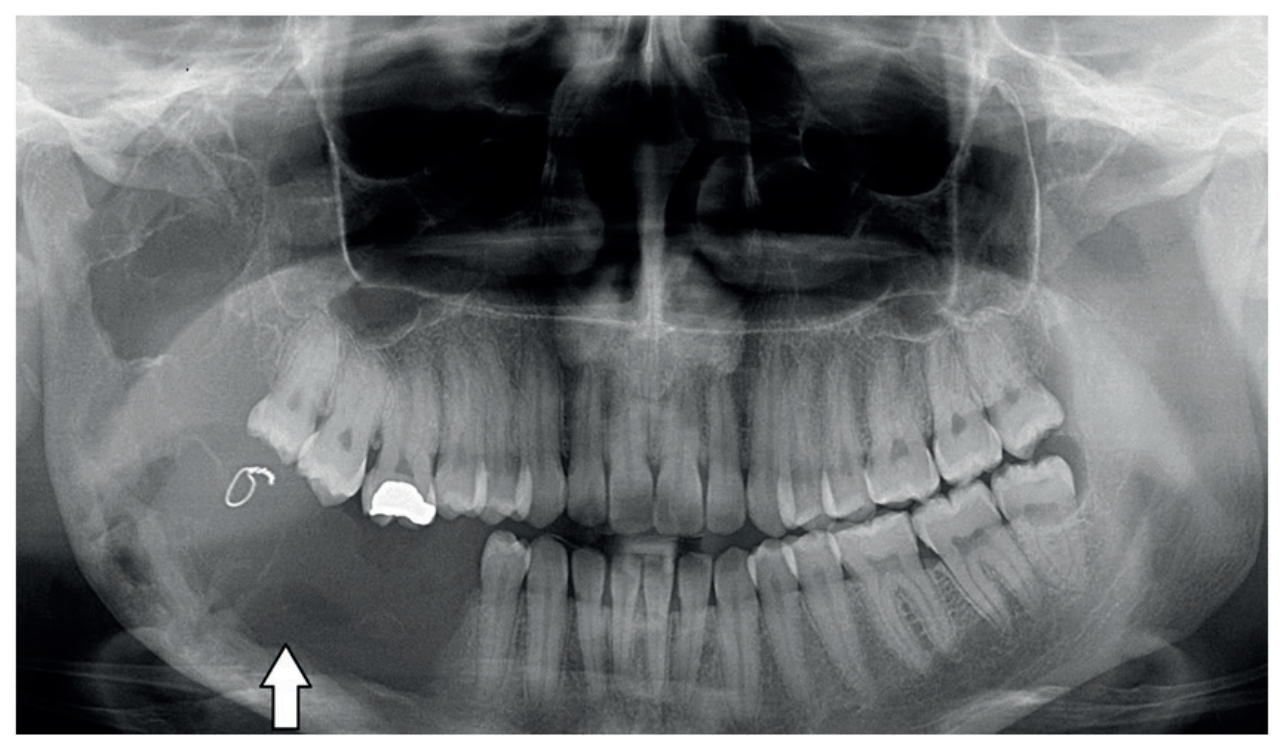

Resim 1. Sağ premolar dişler bölgesinden başlayıp kondil bölgesine kadar uzanan, düzensiz sınırlı, içerisinde sklerotik septaların izlendiği radyolüsent lezyon izlenmektedir (beyaz ok kemikteki defekti göstermektedir). 


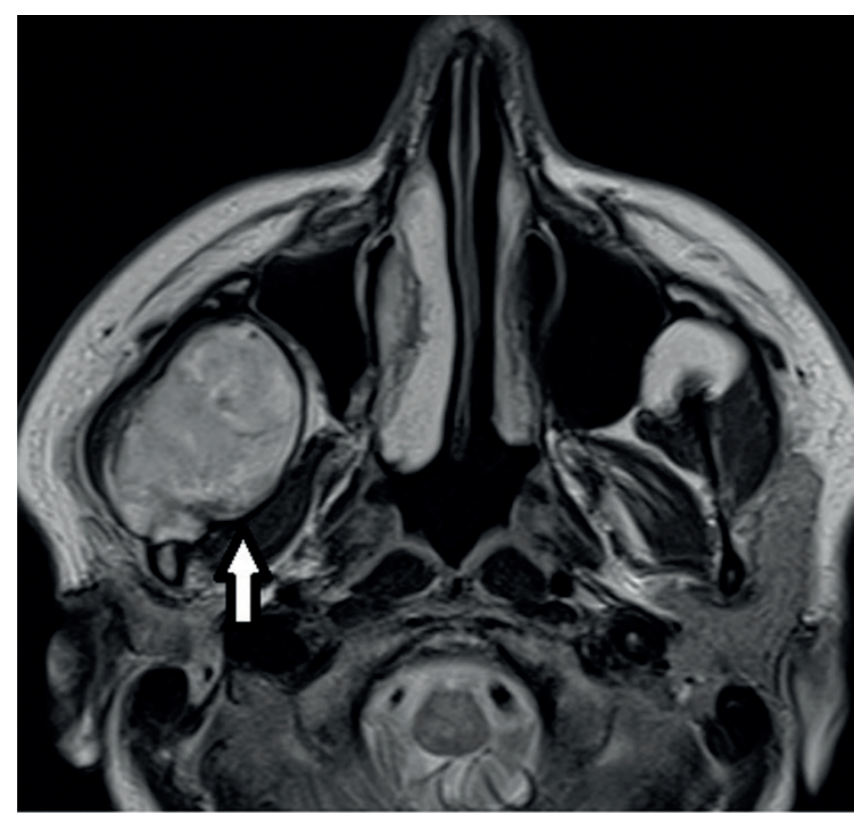

Resim 2. T1A MR kesitlerinde hipointens lezyon izlenmektedir (ok kitle lezyonunu göstermektedir).

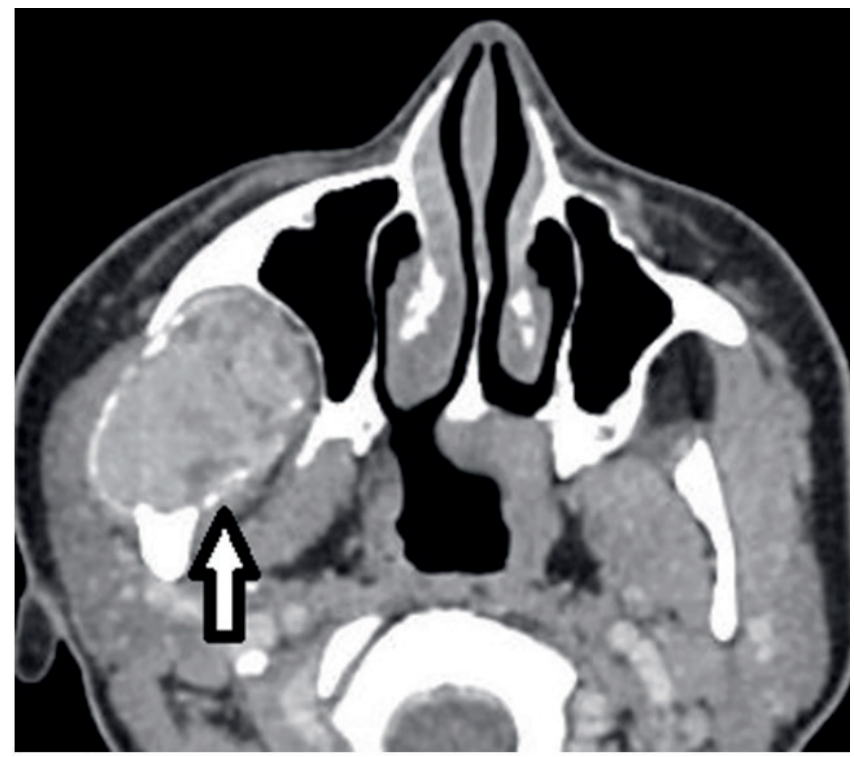

Resim 4. BT'de sağ mandibula kaynaklı hiperdens kitlelezyonu izlenmektedir (ok kitle lezyonunu göstermektedir).

onam formu alınmıştır).

\section{TARTIŞMA}

AFS; benign odontojenik epitel ve malign mezenkimal komponentlerden oluşan nadir bir tümördür (5). Hastalığın optimal tedavisi geniş cerrahi sınırlarla eksizyon ve uzun süreli takiptir (6). Sunulan hastaya hemimandibulektomi yapılarak tümör genişçe eksize edilmiştir. Eğer hastalık yeterli genişlikte cerrahi sınırla eksize edilmezse yüksek

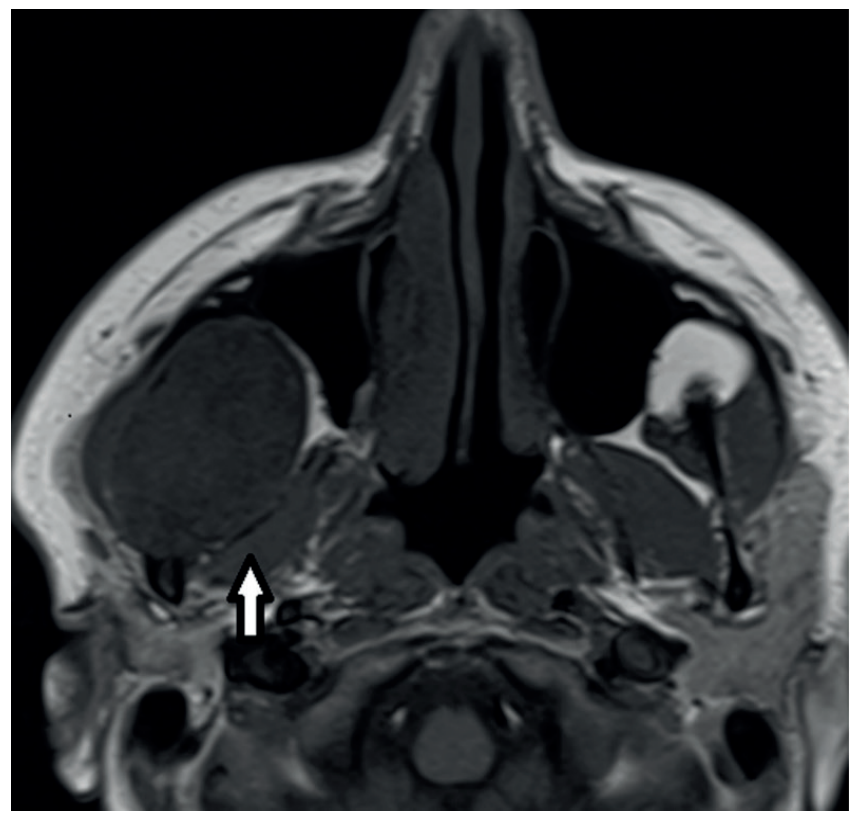

Resim 3. T2 MR kesitlerinde kasa göre hiperintens lezyon izlenmektedir (ok kitle lezyonunu göstermektedir).

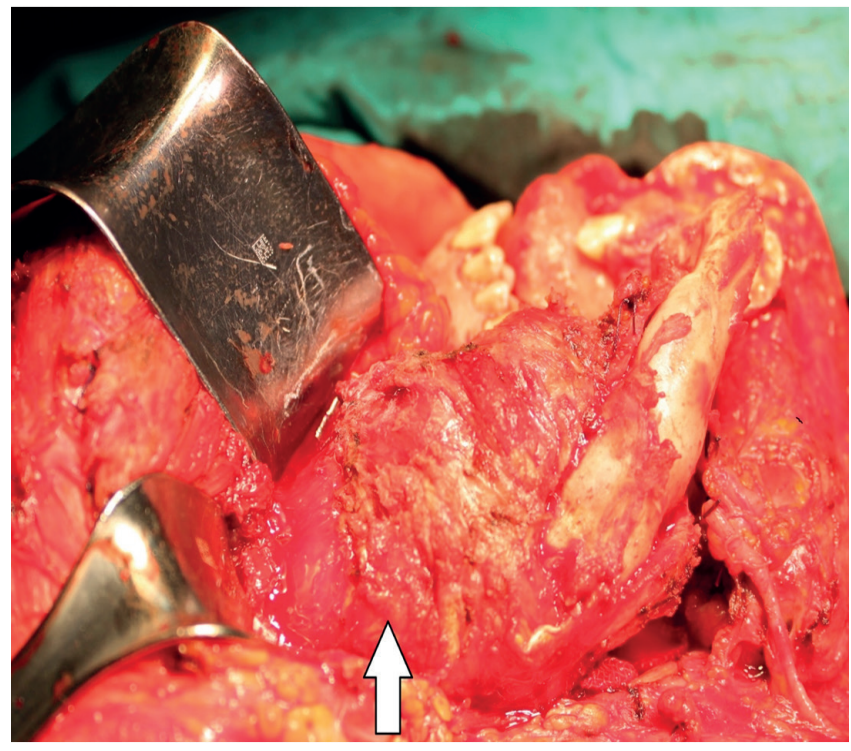

Resim 5. Sağ mandibula kaynaklı tümöral kitleye ait görünüm(ok kitleyi göstermektedir).

rekürrens oranlarıyla beraberdir ve lokal rekürrens varlığında prognoz kötü olmaktadır (7). Hastalık bölgesel ve uzak metastazdan ziyade lokal invazyon yapmaya meyillidir (8). Bu hastalarda uzak metastaz nadir olarak izlenmektedir (9). Pre-operatif PET BT'de herhangi bir uzak metastaz bulgusu saptanmamıştır. Hastalığın tedavisinde proflaktik boyun diseksiyonu tartışmalı bir konudur (10). Hastaya sağ 2.bölge boyun diseksiyonu yapılmış ve patoloji sonucunda herhangi bir metastatik lenf nodu saptanmamıştır. Adjuvan RT/KRT 


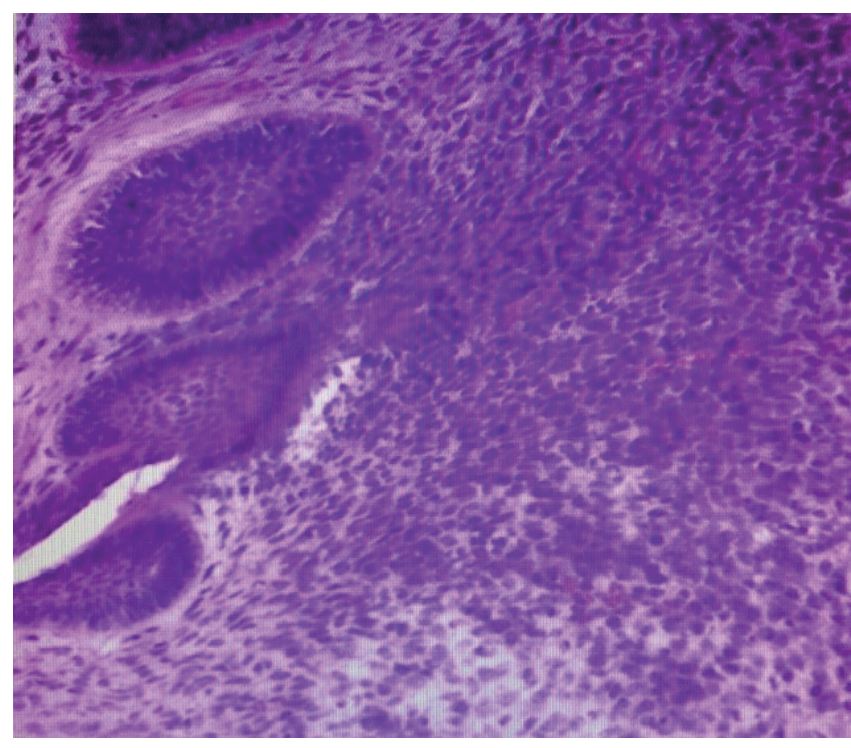

Resim 6. Çevresinde palizatlanma gösteren epitelyal adalardan oluşan ameloblastik komponent ve eşlik eden selüler iğsi hücreli sarkomatoid komponent görülmektedir.

konusunda da net bir görüş yoktur (8). Çünkü hastalığın nadir görülmesi ve uzun dönem takipleriyle ilgili yeterli bilgi olmaması nedeniyle kesin kararlar vermek zordur (9). Fakat AFS'nin yüksek grade bir tümör olması nedeniyle tanı anında subklinik veya mikroskobik metastaz ihtimaline karşılık adjuvan tedavi endikasyonu vardır (10). Bu vakada hastanın patoloji raporu hastalığın fibrosarkom komponentinin high grade olduğu şeklinde raporlanmıştı. Genç hastalarda RT kararı verirken RT’nin lokal rekürrensi azaltmaktaki faydası ile yıllar sonra gelişebilecek sekonder malignite riski arasındaki denge dikkate alınmalıdır (9). Hu ve ark. (8) sundukları vakada cerrahi sonrası hastaya 50 Gy RT verilmiş ve hastanın 6 yıldır takiplerinde nükse rastlanmamıştır. Toplam sağkalım oranlarına bakıldığında 10 yıllık sağkalım \%21.8-83 arasında değişebilmektedir, klinik evre, histolojik grade ve lokal rekürrens en önemli prognostik faktörlerdir (11). Sunulan vakada hastanın yaşının genç, hastalığın prognozunun kötü olması nedeniyle post-operatif KRT uygulanmıştır.

Sonuç olarak; nadir görülen bu hastalıkta cerrahi tedavi ilk seçenek olup adjuvan tedaviler konusunda net bir görüş yoktur. Sunulan vakada hastaya geniş cerrahi eksizyon yapılmış lokal nüks ve uzak metastaz ihtimaline karşı adjuvan KRT uygulanmıştır.

\section{Çıkar Çatışması Beyanı}

Makale yazarları aralarında herhangi bir çıkar çatışmasını olmadığını beyan ederler.

\section{Araştırmacıların Katkı Oranı Beyan Özeti}

Yazarlar makaleye eşit katkı sağlamış olduklarını beyan ederler.

\section{KAYNAKLAR}

1. Leitner C, Hoffmann J, Kroeber S, Reinert S: Low-grade malignant fibrosarcoma of the dental follicle of an unerupted third molar without clinical evidence of any follicular lesion. Journal of Cranio-Maxillofacial Surgery 2007, 35:48-51.

2. Yamaguchi $S$, Nagasawa H, Suzuki T, Fujii E, Iwaki H, Takagi M,et al.: Sarcomas of the oral and maxillofacial region: a review of 32 cases in 25 years. Clinical oral investigations 2004, 8:52-55.

3. Angiero F, Rizzuti T, Crippa R, Stefani M: Fibrosarcoma of the jaws: two cases of primary tumors with intraosseous growth. Anticancer research 2007, 27:2573-2581.

4. Williams MD, Hanna EY, El-Naggar AK: Anaplastic ameloblastic fibrosarcoma arising from recurrent ameloblastic fibroma: restricted molecular abnormalities of certain genes to the malignant transformation. Oral Surgery, Oral Medicine, Oral Pathology, Oral Radiology, and Endodontology 2007, 104:72-75.

5. Dallera P, Bertoni F, Marchetti C, Bacchini P, Campobassi A: Ameloblastic fibrosarcoma of the jaw: report of five cases. Journal of Cranio-Maxillofacial Surgery 1994, 22:349-354.

6. Bregni RC, Taylor AM, García AM: Ameloblastic fibrosarcoma of the mandible: report of two cases and review of the literature. Journal of oral pathology \& medicine 2001, 30:316-320.

7. DeNittis AS, Stambaugh MD, Looby C: Ameloblastic fibrosarcoma of the maxilla: report of a case. Journal of oral and maxillofacial surgery 1998, 56:672-675.

8. Hu YY, Deng MH, Yuan LL, Niu YM: Ameloblastic fibrosarcoma of the mandible: A case report and mini review. Experimental and therapeutic medicine 2014, 8:1463-1466.

9. Pillay RR, Bilski A, Batstone M: Ameloblastic Fibrosarcoma Arising in the Maxilla. The Ochsner Journal 2016, 16:143-145.

10. Greager JA, Reichard K, Campana JP, Gupta TKD: Fibrosarcoma of the head and neck. The American journal of surgery 1994, 167:437-439.

11. Bertoni F, Capanna R, Calderoni P, Patrizia B, Campanacci M: Primary central (medullary) fibrosarcoma of bone. In Seminars in diagnostic pathology1984: 185-198. 
